\title{
Ferric hydrogen sulfate supported on silica-coated nickel ferrite nanoparticles as new and green magnetically separable catalyst for 1,8-dioxodecahydroacridine synthesis
}

\author{
Amir Khojastehnezhad a,*, Mohammad Rahimizadeh a, Hossein Eshghi a , Farid Moeinpour ${ }^{b}$, \\ Mehdi Bakavoli a \\ a Department of Chemistry, Faculty of Sciences, Ferdowsi University of Mashhad, Mashhad, Iran \\ ${ }^{\mathrm{b}}$ Department of Chemistry, Islamic Azad University-Bandar Abbas Branch, Bandar Abbas, 7915893144, Iran
}

\section{A R T I C L E I N F O}

\section{Article history:}

Received 14 September 2013

Accepted 16 December 2013

Published 20 March 2014

\section{Keywords:}

Magnetically separable catalyst

Ferric hydrogen sulfate

Nickel ferrite nanoparticles

1,8-Dioxodecahydroacridine

\section{A B S T R A C T}

A new magnetically separable catalyst consisting of ferric hydrogen sulfate supported on silica-coated nickel ferrite nanoparticles was prepared. The synthesized catalyst was characterized using vibrating sample magnetometry, X-ray diffraction, transmission electron microscopy, scanning electron microscopy, and Fourier transform infrared spectroscopy. This new magnetic catalyst was shown to be an efficient heterogeneous catalyst for the synthesis of 1,8-dioxodecahydroacridines under solvent-free conditions. The catalyst is readily recovered by simple magnetic decantation and can be recycled several times with no significant loss of catalytic activity.

(C) 2014, Dalian Institute of Chemical Physics, Chinese Academy of Sciences. Published by Elsevier B.V. All rights reserved.

\section{Introduction}

In recent years, magnetic nanoparticles (MNPs) have emerged as attractive solid supports for the immobilization of homogeneous catalysts [1,2]. This is because MNPs can be well dispersed in reaction mixtures without a magnetic field, providing a large surface that is readily accessible to substrate molecules. More importantly, after completing the reactions, the MNP-supported catalysts can be isolated efficiently from the product solution through simple magnetic separation, eliminating the need for catalyst filtration and centrifugation $[3,4]$. Among various MNPs, magnetite $\left(\mathrm{Fe}_{3} \mathrm{O}_{4}\right)$ is the material most widely used for catalyst supports $[5,6]$. However, $\mathrm{Fe}_{3} \mathrm{O}_{4}$ is fairly reactive in acidic environments, and because it contains $\mathrm{Fe}^{2+}$, which is readily oxidized, $\mathrm{Fe}_{3} \mathrm{O}_{4}$ MNPs are vulnerable to loss of magnetism. In contrast, nickel ferrite $\left(\mathrm{NiFe}_{2} \mathrm{O}_{4}\right)$, which is a typical spinel-structured ferromagnetic oxide, has high thermal stability, moderate magnetization, and mechanical hardness $[7,8]$. Nickel ferrite therefore performs better than magnetite as a support for homogeneous catalysts. Currently, much attention is focused on the synthesis of magnetic core-shell structures by coating preformed MNPs with silica shells. Nanosized silica, which is non-toxic and can be grafted with various surface modifiers, has great potential in many applications [9]. Silica-gel-supported ferric hydrogen sulfate ( $\left.\mathrm{SiO}_{2}-\mathrm{FHS}\right)$ has become a popular catalyst in organic synthesis $[10,11]$. Some of the advantages of using supported FHS rather than a homogeneous catalyst are easier recovery and recycling after reactions, and easier product separation. However, the separation and recovery of immobilized FHS are usually performed by filtration or centrifugation, which are not eco-friendly processes. The immobilization of FHS on silica-coated $\mathrm{NiFe}_{2} \mathrm{O}_{4}$ NPs

\footnotetext{
* Corresponding author. Tel: +98-511-8797022; Fax: +98-511-8796416; E-mail: akhojastehnezhad@yahoo.com This work was supported by Ferdowsi University of Mashhad, Mashhad, Iran. DOI: 10.1016/S1872-2067(14)60001-2 | http://www.sciencedirect.com/science/journal/18722067 | Chin. J. Catal., Vol. 35, No. 3, March 2014
} 
$\left(\mathrm{NiFe}_{2} \mathrm{O}_{4} @ \mathrm{SiO}_{2}\right.$-FHS) can be used to produce a novel heterogeneous catalyst system that has both high separation efficiency and a relatively high surface area to maximize catalyst loading and activity. Based on these factors, we synthesized $\mathrm{NiFe}_{2} \mathrm{O}_{4} @ \mathrm{SiO}_{2}$-FHS as a novel nanomagnetically recoverable catalyst and assessed its catalytic activity in the synthesis of 1,8-decahydroacridines under solvent-free conditions.

Acridine and acridine-1,8-dione derivatives are polyfunctionalized 1,4-dihydropyridine derivatives. They have a wide range of pharmacological properties such as antimalarial [12], anticancer [13], cytotoxic [14], and antimicrobial [15] activities, and are widely prescribed as calcium $\beta$-blockers [16]. Also, 1,8-dioxodecahydroacridines have been used as laser dyes [17] and photoinitiators [18]. Many procedures for the synthesis of acridine derivatives containing 1,4-dihydropyridines by the reaction of dimedone, aldehydes, and different nitrogen sources in the presence of various catalysts have been reported [19-28]. Most of these methods suffer from disadvantages such as harsh condition, low yields, very high reaction temperatures, and expensive reagents. Based on our interest in the synthesis of heterocyclic compounds and in continuation of our previous work on the use of reusable catalysts in organic reactions [29-31], we report a new efficient and green method for 1,8dioxodecahydroacridines synthesis using $\mathrm{NiFe}_{2} \mathrm{O}_{4} @ \mathrm{SiO}_{2}-\mathrm{FHS}$ as a catalyst (Scheme 1). To the best of our knowledge, this is the first report of the synthesis, characterization, and catalytic performance of $\mathrm{NiFe}_{2} \mathrm{O}_{4} @ \mathrm{SiO}_{2}-\mathrm{FHS}$.

\section{Experimental}

All chemicals were available commercially and used without further purification. Melting points were recorded using an electrothermal 9100 melting point apparatus. Fourier transform infrared (FT-IR) spectra were obtained with a 4300 Shimadzu spectrometer using $\mathrm{KBr}$ disks. ${ }^{1} \mathrm{H}$ nuclear magnetic resonance (NMR; $500 \mathrm{MHz}$ ) spectra were recorded using a Bruker DRX500 spectrometer. X-ray diffraction (XRD) was performed using a PANalytical X'Pert Pro X-ray diffractometer. The surface morphology and particle size were studied using scanning electron microscopy (SEM; Hitachi S-4800). Transmission electron microscopy (TEM) was performed using a Hitachi H-7650 microscope at $80 \mathrm{kV}$.

\subsection{Preparation of catalyst $\left(\mathrm{NiFe}_{2} \mathrm{O}_{4} @ \mathrm{SiO}_{2}-\mathrm{FHS}\right)$}

A solution consisting of $\mathrm{FeCl}_{3}(160 \mathrm{~mL}, 1 \mathrm{~mol} / \mathrm{L})$ and $\mathrm{NiCl}_{2}$ ( $40 \mathrm{~mL}, 1 \mathrm{~mol} / \mathrm{L}$ ) was poured as quickly as possible into a boiling alkaline solution $(\mathrm{NaOH}, 1000 \mathrm{~mL}, 1 \mathrm{~mol} / \mathrm{L})$ under vigorous stirring. The solution was then cooled and stirred continuously for $90 \mathrm{~min}$. The resulting precipitate was purified four times by centrifugation (4000-6000 r/min, $20 \mathrm{~min}$ ) and decantation. A layer of silica was coated on the surfaces of the $\mathrm{NiFe}_{2} \mathrm{O}_{4} \mathrm{NPs}$ by first ultrasonically dispersing the NPs $(8 \% \mathrm{w} / \mathrm{w}, 25 \mathrm{~mL})$ in ethanol for $2 \mathrm{~h}$ at $60{ }^{\circ} \mathrm{C}$. A concentrated ammonia solution was added, and the resulting mixture was stirred at $60{ }^{\circ} \mathrm{C}$ for 40 min. Tetraethyl orthosilicate $(4.0 \mathrm{~mL})$ was added, and the reaction mixture was continuously stirred at $60{ }^{\circ} \mathrm{C}$ for $24 \mathrm{~h}$. The silica-coated NPs were collected using an external magnet, followed by washing three times with methanol and drying in a vacuum for $48 \mathrm{~h}$. The resulting MNPs were calcined at $800{ }^{\circ} \mathrm{C}$ for 4 h. A round-bottomed flask was charged with FHS (1.0 g), and absolute ethanol (50 mL) was added. The mixture was stirred at room temperature for $30 \mathrm{~min}$. $\mathrm{NiFe}_{2} \mathrm{O}_{4} @ \mathrm{SiO}_{2}$ (2.5 g) was then added to the solution, and the mixture was stirred for another $12 \mathrm{~h}$. The mixture was filtered, and the residue was dried at $100{ }^{\circ} \mathrm{C}$ for $2 \mathrm{~h}$. A brown homogeneous powder was obtained; it was stored in a desiccator.

\subsection{Typical procedure for synthesis of 1,8-dioxodecahydroacridines $\mathbf{4 a - 4 n}$}

A mixture of an aromatic aldehyde $\mathbf{1}(1 \mathrm{mmol})$, dimedone $\mathbf{2}$ (2 mmol), ammonium acetate or an aromatic amine 3 (1 mmol), and $\mathrm{NiFe}_{2} \mathrm{O}_{4} @ \mathrm{SiO}_{2}$-FHS (0.025 g, 2.4 mol\%) was heated in an oil-bath at $80^{\circ} \mathrm{C}$ for $15-30 \mathrm{~min}$. During the procedure, the reaction was monitored using thin-layer chromatography. When the reaction was complete, the mixture was cooled to room temperature and chloroform was added. The catalyst was insoluble in chloroform and could be deposited on the side walls of the reaction vessel using an external magnet; the reaction solution was decanted to another vessel. The catalyst was then washed with chloroform and dried for reuse in the next run. The products were collected and recrystallized from ethanol to give compounds $\mathbf{4 a - 4 n}$ in high yields.

\subsection{Selected ${ }^{1} H$ NMR data}

3,3,6,6-Tetramethyl-1,8-dioxo-9-(4-chlorophenyl)decahydr oacridine (4a). ${ }^{1} \mathrm{H}$ NMR (500 MHz, $\left.\mathrm{CDCl}_{3}\right): \delta 1.00(\mathrm{~s}, 6 \mathrm{H}, 2 \mathrm{Me})$, 1.12 (s, 6H, 2Me), 2.19 (d, $J=16.3 \mathrm{~Hz}, 2 \mathrm{H}$ ), 2.27 (d, $J=16.3 \mathrm{~Hz}$, 2H), 2.29 (d, $J=16.7 \mathrm{~Hz}, 2 \mathrm{H}$ ), 2.41 (d, $J=16.7 \mathrm{~Hz}, 2 \mathrm{H}), 5.07$ (s, $1 \mathrm{H}, \mathrm{CH}), 6.68$ (s br, 1H, NH), 7.19 (d, J = 8.4 Hz, 2H, aromatic), 7.30 (d, $J=8.4 \mathrm{~Hz}, 2 \mathrm{H}$, aromatic).

3,3,6,6-Tetramethyl-1,8-dioxo-9-(4-nitrophenyl)decahydroa cridine (4h). ${ }^{1} \mathrm{H}$ NMR (500 MHz, $\left.\mathrm{CDCl}_{3}\right): \delta 1.00$ (s, 6H, 2Me), 1.14 (s, 6H, 2Me), 2.19 (d, $J=16.5 \mathrm{~Hz}, 2 \mathrm{H}$ ), 2.28 (d, $J=16.5 \mathrm{~Hz}$,

$$
\mathrm{R}=\mathrm{C}_{6} \mathrm{H}_{5}, 4-\mathrm{MeC}_{6} \mathrm{H}_{4}, 4-\mathrm{MeOC}_{6} \mathrm{H}_{4}
$$

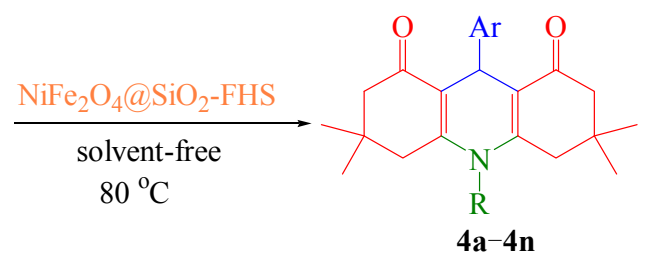

Scheme 1. Synthesis of 1,8-dioxodecahydroacridines in the presence of $\mathrm{NiFe}_{2} \mathrm{O}_{4} @ \mathrm{SiO}_{2}$-FHS. 


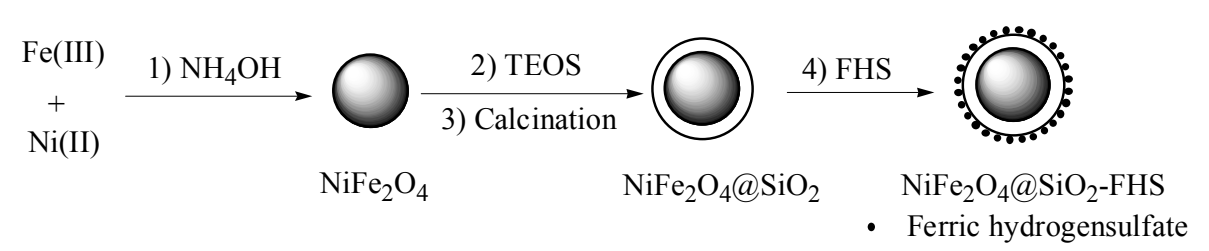

Scheme 2. Preparation of $\mathrm{NiFe}_{2} \mathrm{O}_{4} @ \mathrm{SiO}_{2}$-FHS.

2H), 2.32 (d, $J=16.7 \mathrm{~Hz}, 2 \mathrm{H}), 2.46$ (d, $J=16.7 \mathrm{~Hz}, 2 \mathrm{H}$ ), 5.19 (s, $1 \mathrm{H}, \mathrm{CH}$ ), 6.12 (s br, 1H, NH), 7.54 (d, J = 8.7 Hz, 2H, aromatic), $8.10(\mathrm{~d}, J=8.7 \mathrm{~Hz}, 2 \mathrm{H}$, aromatic).

\section{Results and discussion}

\subsection{Preparation and characterization of $\mathrm{NiFe}_{2} \mathrm{O}_{4} @ \mathrm{SiO}_{2}-\mathrm{FHS}$}

$\mathrm{NiFe}_{2} \mathrm{O}_{4} @ \mathrm{SiO}_{2}$ nanocrystallites were prepared according to the procedure reported by Massart et al. [32], with minor modifications: fine particles were precipitated in an alkaline solution (Scheme 2).

The $\mathrm{NiFe}_{2} \mathrm{O}_{4} @ \mathrm{SiO}_{2}$-FHS nanocrystallites were characterized using FT-IR. The $\mathrm{NiFe}_{2} \mathrm{O}_{4} @ \mathrm{SiO}_{2}$ nanocrystallites were characterized using TEM and SEM, and $\mathrm{NiFe}_{2} \mathrm{O}_{4}$ was characterized using XRD and vibrating sample magnetometry (VSM).

The FT-IR spectra of $\mathrm{NiFe}_{2} \mathrm{O}_{4} @ \mathrm{SiO}_{2}$, FHS, and $\mathrm{NiFe}_{2} \mathrm{O}_{4} @ \mathrm{SiO}_{2}-$ FHS are shown in Fig. 1 . In the FT-IR spectrum of $\mathrm{NiFe}_{2} \mathrm{O}_{4} @$ $\mathrm{SiO}_{2}$-FHS, bands corresponding to $\mathrm{NiFe}_{2} \mathrm{O}_{4} @ \mathrm{SiO}_{2}$ and FHS, but slightly shifted, are observed; this shows that FHS was well adsorbed on the silica surface. The FT-IR spectrum of $\mathrm{NiFe}_{2} \mathrm{O}_{4} @ \mathrm{SiO}_{2}$ exhibits strong bands in the low-frequency region (1000-500 $\mathrm{cm}^{-1}$ ) from the iron oxide skeleton, in agreement with the spectrum for magnetite. The characteristic bands from Si-O-Fe and Si-O are observed at 798 and $1087 \mathrm{~cm}^{-1}$, respectively. The peaks at $1440-1650 \mathrm{~cm}^{-1}$ show the presence of $\mathrm{Fe}-\mathrm{O}$. The spectrum of $\mathrm{NiFe}_{2} \mathrm{O}_{4} @ \mathrm{SiO}_{2}$-FHS also shows broad $\mathrm{OH}$ stretching absorptions at around 3500 and $3100 \mathrm{~cm}^{-1}$. The sulfuric acid functional groups in $\mathrm{Fe}\left(\mathrm{HSO}_{4}\right)_{3}$ show FT-IR absorptions of the $\mathrm{O}=\mathrm{S}=0$ stretching mode at $1180 \mathrm{~cm}^{-1}$ and the S-0 stretching mode at $600-700 \mathrm{~cm}^{-1}$.

TEM and SEM photographs of the samples are shown in Fig.

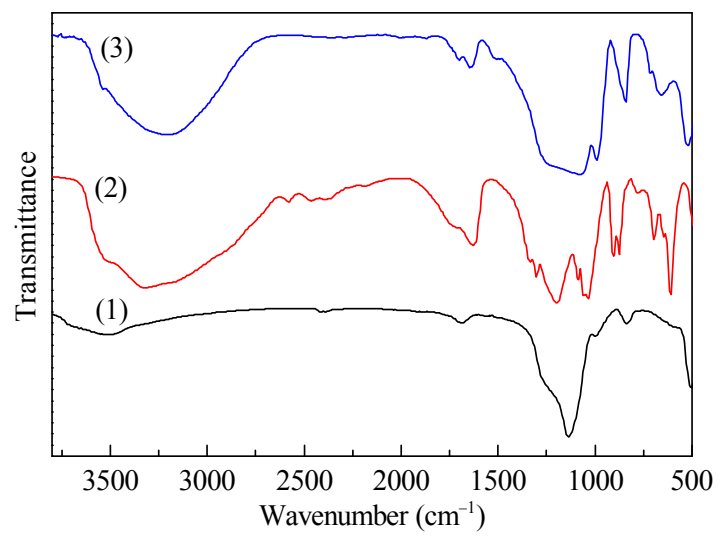

Fig. 1. FT-IR spectra of $\mathrm{NiFe}_{2} \mathrm{O}_{4} @ \mathrm{SiO}_{2}$ (1), $\mathrm{FHS}(2)$, and $\mathrm{NiFe}_{2} \mathrm{O}_{4} @ \mathrm{SiO}_{2}-$ FHS (3).
2 and Fig. 3, respectively. They show that the prepared MNPs are spherical, narrowly distributed, and well dispersed, with an average diameter less than $50 \mathrm{~nm}$.

To confirm $\mathrm{NiFe}_{2} \mathrm{O}_{4}$ formation in the synthesized MNPs, the XRD spectrum of the sample was studied. The XRD pattern (Fig. 4) indicates that these NPs have the spinel structure, with all the major peaks matching the standard pattern of bulk $\mathrm{NiFe}_{2} \mathrm{O}_{4}$ (JCPDS 10-325).

It is important that the core-shell material has sufficient magnetic and superparamagnetic properties for practical applications. Magnetic hysteresis measurements were performed on $\mathrm{NiFe}_{2} \mathrm{O}_{4}$ in an applied magnetic field at room temperature, with field sweeping from -10000 to +10000 0e. As shown in Fig. 5, the $\mathrm{M}(\mathrm{H})$ hysteresis loop for the sample was completely reversible, showing that the NPs have superparamagnetic characteristics. The hysteresis loops reached saturation at the maximum applied magnetic field. The magnetic saturation value of $\mathrm{NiFe}_{2} \mathrm{O}_{4}$ is $16.71 \mathrm{emu} / \mathrm{g}$ at room temperature. The particles showed high permeability magnetization, and their mag-

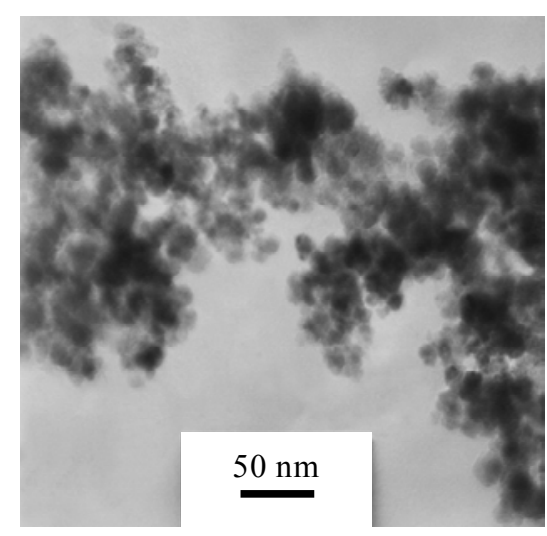

Fig. 2. TEM image of $\mathrm{NiFe}_{2} \mathrm{O}_{4} @ \mathrm{SiO}_{2} \mathrm{NPs}$.

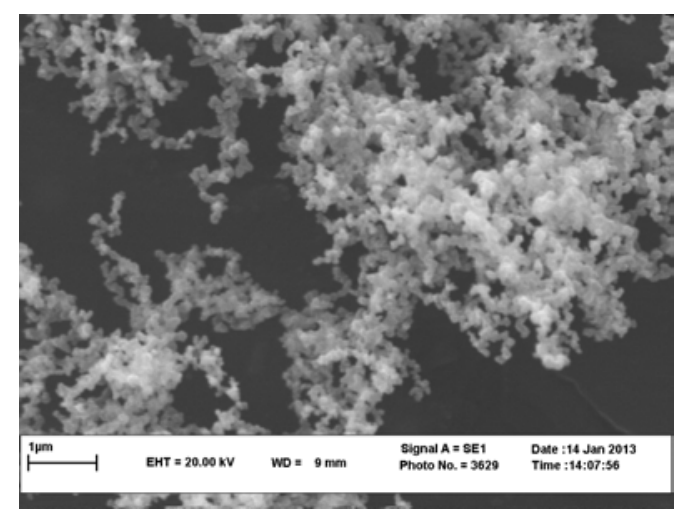

Fig. 3. SEM image of $\mathrm{NiFe}_{2} \mathrm{O}_{4} @ \mathrm{SiO}_{2} \mathrm{NPs}$. 


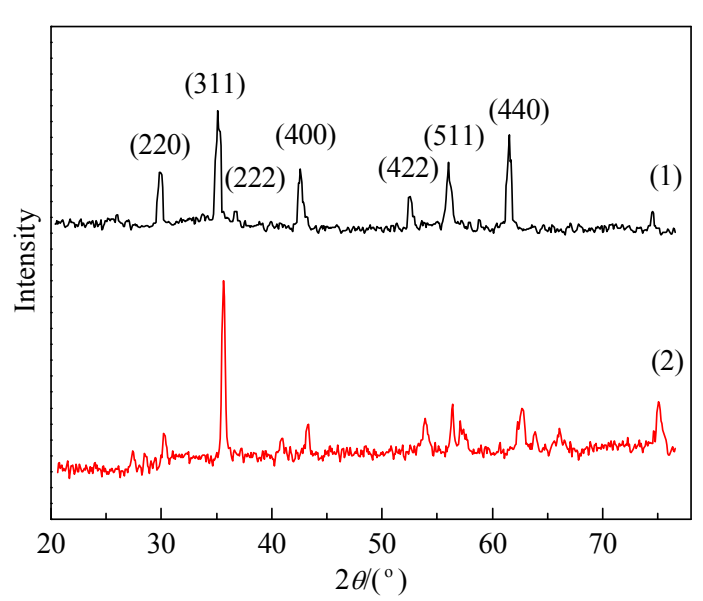

Fig. 4. XRD patterns of $\mathrm{NiFe}_{2} \mathrm{O}_{4}$. (1) Standard pattern of bulk $\mathrm{NiFe}_{2} \mathrm{O}_{4}$ (JCPDS 10-325); (2) Synthesized $\mathrm{NiFe}_{2} \mathrm{O}_{4} \mathrm{NPs}$.

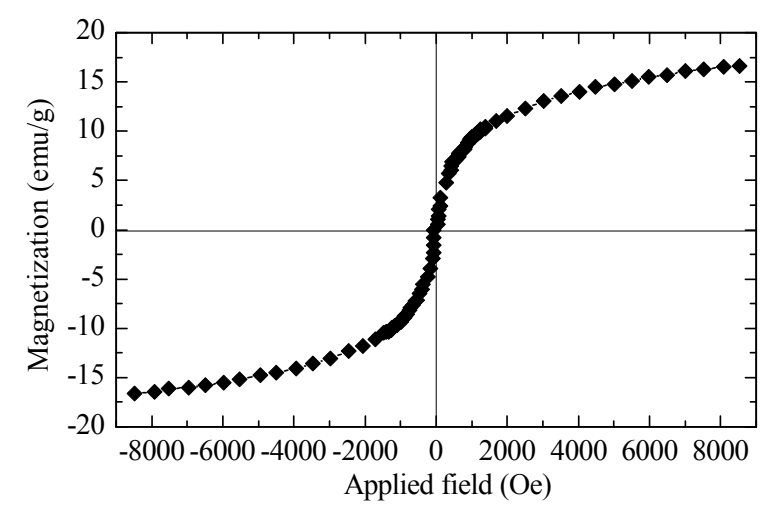

Fig. 5. VSM curve of $\mathrm{NiFe}_{2} \mathrm{O}_{4}$ at room temperature.

netization was sufficient for magnetic separation using a conventional magnet (Fig. 5).

\subsection{One-pot synthesis of 1,8-dioxodecahydroacridines}

The one-pot synthesis of 1,8-dioxodecahydroacridines was achieved by the three-component condensation of dimedone, aromatic aldehydes, and ammonium acetate or aromatic amines in the presence of $\mathrm{NiFe}_{2} \mathrm{O}_{4} @ \mathrm{SiO}_{2}-\mathrm{FHS}$ as a heterogeneous catalyst (Scheme 1). The synthesis of compound 4 a was
Table 1

Effect of the $\mathrm{NiFe}_{2} \mathrm{O}_{4} @ \mathrm{SiO}_{2}$-FHS amount on model reaction.

\begin{tabular}{lcccc}
\hline Entry & $\begin{array}{c}\text { Catalyst } \\
(\mathrm{g})\end{array}$ & $\begin{array}{c}\text { Time } \\
(\mathrm{min})\end{array}$ & $\begin{array}{c}\text { Temperature } \\
\left({ }^{\circ} \mathrm{C}\right)\end{array}$ & $\begin{array}{c}\text { Yield a }^{\mathrm{a}} \\
(\%)\end{array}$ \\
\hline 1 & None & 120 & 80 & 0 \\
2 & 0.005 & 30 & 80 & 49 \\
3 & 0.010 & 15 & 80 & 63 \\
4 & 0.025 & 15 & 80 & 92 \\
5 & 0.050 & 15 & 80 & 93 \\
6 & 0.100 & 15 & 80 & 93 \\
7 & 0.025 & 15 & 90 & 92 \\
8 & 0.025 & 15 & 100 & 92 \\
9 & 0.025 & 15 & 120 & 93 \\
\hline
\end{tabular}

Reaction conditions: 4-chlorobenzaldehyde $(1 \mathrm{mmol})$, dimedone $(2$ mmol), ammonium acetate $(1 \mathrm{mmol}) .{ }^{\text {a }}$ Isolated yield.

selected as a model reaction to optimize the reaction conditions. The reaction was carried out by heating a mixture of 4-chlorobenzaldehyde (1 mmol), dimedone (2 mmol), and ammonium acetate ( $1 \mathrm{mmol}$ ) under various conditions.

The efficiency of the reaction is mainly affected by the amount of $\mathrm{NiFe}_{2} \mathrm{O}_{4} @ \mathrm{SiO}_{2}$-FHS (Table 1). No product was obtained in the absence of the catalyst (entry 1), indicating that the catalyst is necessary for the reaction. The yield of product 4a increased with increasing amount of catalyst (entries 2 and 3). The optimum amount of $\mathrm{NiFe}_{2} \mathrm{O}_{4} @ \mathrm{SiO}_{2}$-FHS was $0.025 \mathrm{~g}$ (entry 4); further increasing the amount of catalyst did not noticeably increase the yield (entries 5 and 6). The reaction was also carried out at different temperatures under solvent-free conditions. Increasing the temperature did not improve the yield (entries 7-9). The best result was obtained at $80{ }^{\circ} \mathrm{C}$ for $15 \mathrm{~min}$, therefore all subsequent reactions were carried out at $80{ }^{\circ} \mathrm{C}$ in the presence of $0.025 \mathrm{~g}$ of $\mathrm{NiFe}_{2} \mathrm{O}_{4} @ \mathrm{SiO}_{2}$ FHS under solvent-free conditions.

Using these optimized reaction conditions, the scope and efficiency of this approach were explored for the synthesis of a wide variety of 1,8-dioxodecahydroacridines; the results are summarized in Table 2 . All the reactions gave high product yields and tolerated a range of aromatic amines, either unsubstituted or with electron-donating groups, and a wide range of aromatic aldehydes bearing electron-donating and electron-withdrawing substituents. In all cases, the obtained product was isolated using a simple work-up.

Table 2

Synthesis of 1,8-dioxodecahydroacridines using $\mathrm{NiFe}_{2} \mathrm{O}_{4} @ \mathrm{SiO}_{2}$-FHS $(0.025 \mathrm{~g})$ as catalyst.

\begin{tabular}{|c|c|c|c|c|c|c|c|c|c|c|c|c|c|c|c|}
\hline $\begin{array}{l}\text { En- } \\
\text { try }\end{array}$ & $\mathrm{Ar}$ & $\mathrm{R}$ & Product $^{\mathrm{a}}$ & & $\begin{array}{l}\text { Time } \\
\text { (min) }\end{array}$ & $\begin{array}{c}\text { Yield }^{\mathrm{b}} \\
(\%)\end{array}$ & $\begin{array}{c}\text { Melting } \\
\text { point }^{\mathrm{c}}\left({ }^{\circ} \mathrm{C}\right)\end{array}$ & $\begin{array}{l}\text { En- } \\
\text { try }\end{array}$ & $\mathrm{Ar}$ & $\mathrm{R}$ & Product $^{a}$ & & $\begin{array}{l}\text { Time } \\
(\mathrm{min})\end{array}$ & $\begin{array}{c}\text { Yield b } \\
(\%)\end{array}$ & $\begin{array}{c}\text { Melting } \\
\text { point }{ }^{\circ}\left({ }^{\circ} \mathrm{C}\right)\end{array}$ \\
\hline 1 & $4-\mathrm{ClC}_{6} \mathrm{H}_{4}$ & $\mathrm{H}$ & & $4 a$ & 15 & 92 & $\begin{array}{c}299-300 \\
(300-302)\end{array}$ & 3 & $2-\mathrm{ClC}_{6} \mathrm{H}_{4}$ & $\mathrm{H}$ & & $4 c$ & 20 & 94 & $\begin{array}{c}221-222 \\
(220-222)\end{array}$ \\
\hline 2 & 4- $\mathrm{BrC}_{6} \mathrm{H}_{4}$ & $\mathrm{H}$ & & $4 b$ & 18 & 91 & $\begin{array}{c}240-242 \\
(239-242)\end{array}$ & 4 & $\mathrm{C}_{6} \mathrm{H}_{5}$ & $\mathrm{H}$ & & $4 d$ & 20 & 92 & $\begin{array}{c}191-192 \\
(192-195)\end{array}$ \\
\hline
\end{tabular}


Table 2 (Continued)

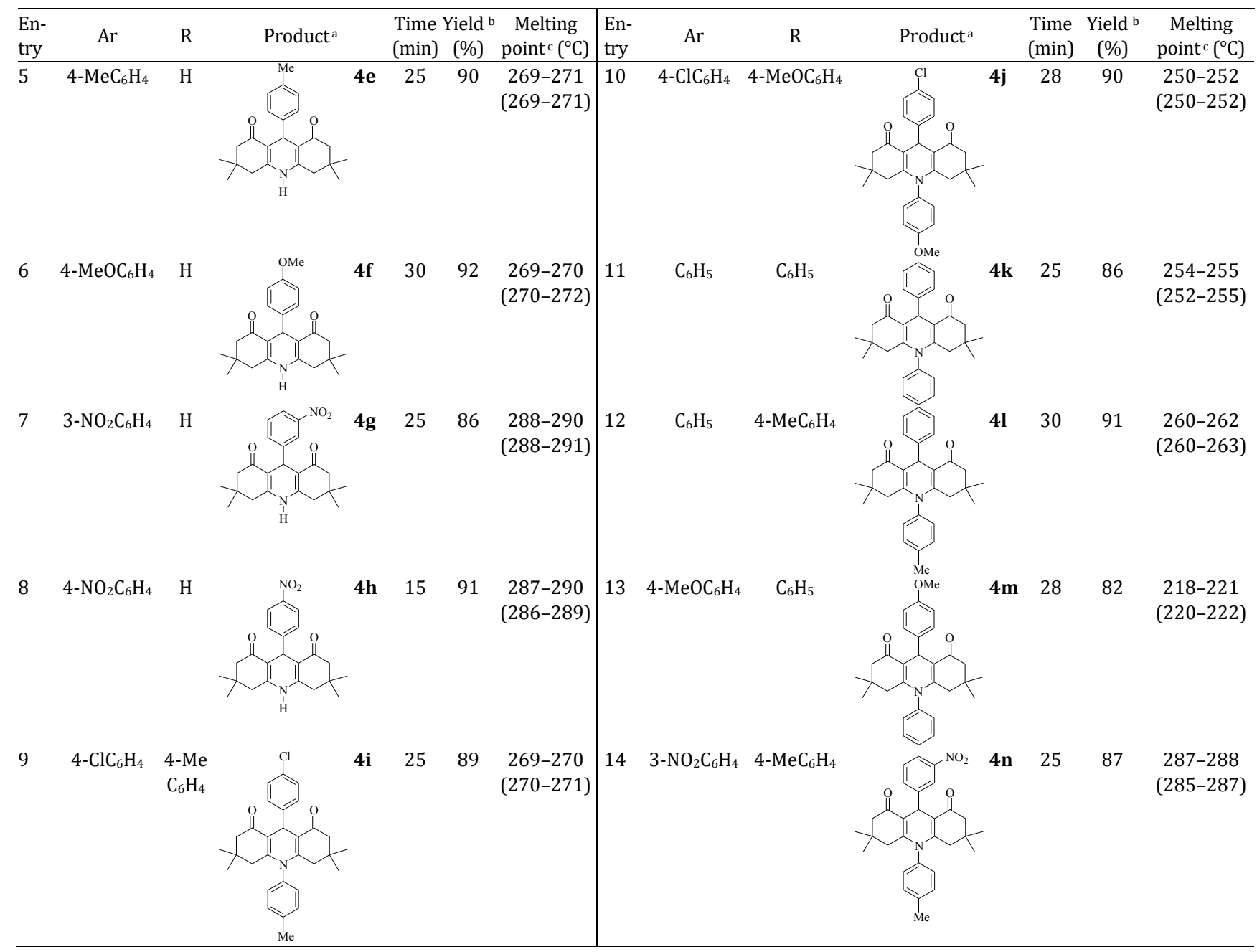

Reaction conditions: $1 \mathrm{mmol}$ aromatic aldehyde, $2 \mathrm{mmol}$ dimedone, $1 \mathrm{mmol}$ ammonium acetate or aromatic amines, $80{ }^{\circ} \mathrm{C}$.

a All the products were characterized by IR spectral data and comparison of their melting points with those of authentic samples. Also, the structures of some products were confirmed by ${ }^{1} \mathrm{H}$ NMR spectral data.

b Isolated yield.

c The data in parentheses were reported in Ref. [23].

The catalyst reusability was also investigated. For this purpose, the same model reaction was again studied under the optimized conditions. After completion of the reaction, chloroform was added to the reaction mixture to dissolve the product. An external magnet was used to deposit the catalyst on the side walls of the reaction vessel, and the solution was decanted. The catalyst was washed with chloroform, dried at $100{ }^{\circ} \mathrm{C}$ under vacuum for $1 \mathrm{~h}$, and reused for a similar reaction. As shown in Fig. 6, the catalyst could be reused at least five times without significant loss of activity.

A proposed mechanism for the condensation of an aromatic aldehyde, dimedone, and ammonium acetate or an aromatic amine in the presence of $\mathrm{NiFe}_{2} \mathrm{O}_{4} @ \mathrm{SiO}_{2}$-FHS (as a Brönsted acidic catalyst) for the synthesis of 1,8-dioxodecahydroacridines is shown in Scheme 3.

To show the merit of the present work, we compared the results using $\mathrm{NiFe}_{2} \mathrm{O}_{4} @ \mathrm{SiO}_{2}$-FHS in the synthesis of 1,8-dioxodecahydroacridines (benzaldehyde) with those obtained using other solid acids such as $\mathrm{B}\left(\mathrm{C}_{6} \mathrm{~F}_{5}\right)_{3}, \mathrm{SiO}_{2}-\mathrm{PrSO}_{3} \mathrm{H}$, silica-supported Preyssler NPs (SPNP), L-proline, and FSG-Hf( $\left(\mathrm{NPf}_{2}\right)_{4}$. As shown in Table 3, $\mathrm{NiFe}_{2} \mathrm{O}_{4} @ \mathrm{SiO}_{2}$-FHS is the most efficient catalyst and gives high yields of products in

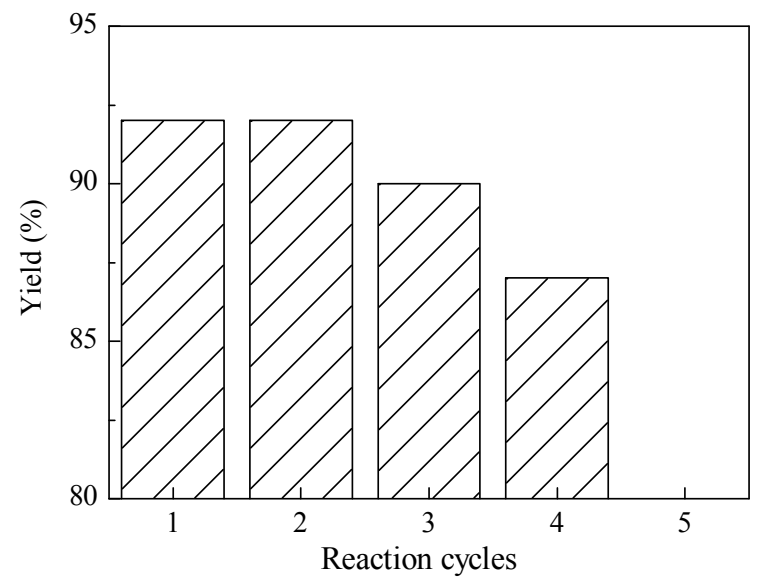

Fig. 6. Catalyst reusability tests. 


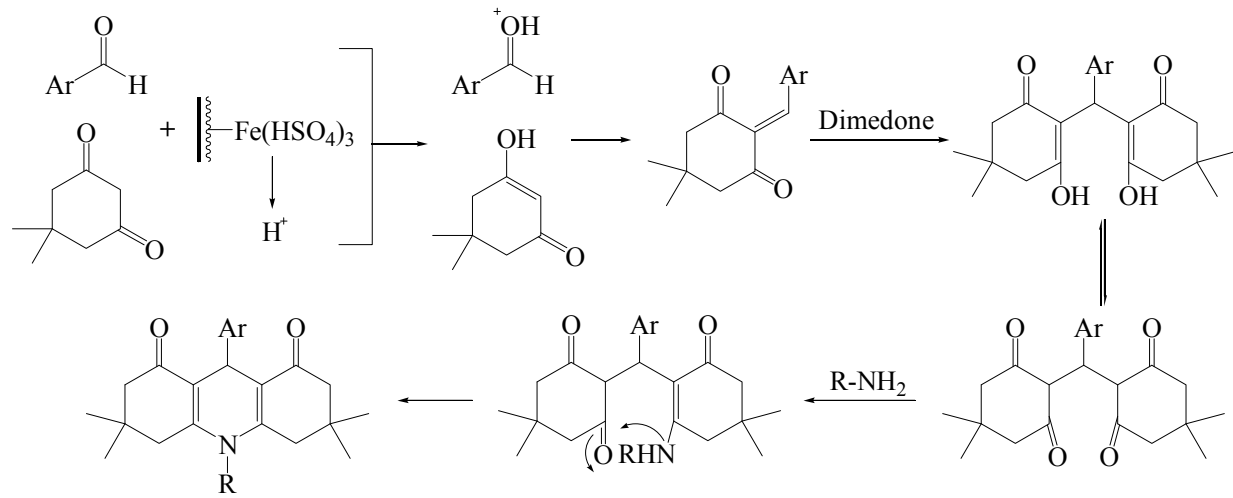

Scheme 3. Suggested mechanism for preparation of 1,8-dioxodecahydroacridines.

Table 3

Comparison of $\mathrm{NiFe}_{2} \mathrm{O}_{4} @ \mathrm{SiO}_{2}$-FHS with other solid acids.

\begin{tabular}{|c|c|c|c|c|c|}
\hline Entry & Catalyst & Conditions & $\begin{array}{l}\text { Time } \\
(\mathrm{min})\end{array}$ & $\begin{array}{l}\text { Yield } \\
(\%)\end{array}$ & Ref. \\
\hline 1 & $\mathrm{NiFe}_{2} \mathrm{O}_{4} @ \mathrm{SiO}_{2}$-FHS & solvent free, $80^{\circ} \mathrm{C}$ & 20 & 92 & this study \\
\hline 2 & $\mathrm{~B}\left(\mathrm{C}_{6} \mathrm{~F}_{5) 3}\right.$ & solvent free, $100^{\circ} \mathrm{C}$ & 210 & 80 & [33] \\
\hline 3 & $\mathrm{SiO}_{2}-\mathrm{Pr}-\mathrm{SO}_{3} \mathrm{H}$ & solvent free, $120^{\circ} \mathrm{C}$ & 120 & 85 & [28] \\
\hline 4 & SPNP & $\mathrm{H}_{2} \mathrm{O}$, reflux & 120 & 91 & {$[34]$} \\
\hline 5 & L-Proline & $\mathrm{H}_{2} \mathrm{O}$, & 180 & 84 & [35] \\
\hline 6 & FSG-Hf(NPf $)_{4}$ & $\mathrm{C}_{2} \mathrm{H}_{5}$, reflux & 240 & 82 & [36] \\
\hline
\end{tabular}

shorter times. In addition, the advantages of $\mathrm{NiFe}_{2} \mathrm{O}_{4} @ \mathrm{SiO}_{2}-\mathrm{FHS}$ are its recyclability and very simple work-up.

\section{Conclusions}

$\mathrm{NiFe}_{2} \mathrm{O}_{4} @ \mathrm{SiO}_{2}$-FHS was successfully used as a new, green, and powerful catalyst for the synthesis of 1,8-dioxodecahydroacridines at $80{ }^{\circ} \mathrm{C}$ and under solvent-free conditions. The catalyst was recovered after a very simple work-up (with the aid of an external magnet) and reused at least five times without appreciable loss of catalytic activity. The present method requires a small amount ( $0.025 \mathrm{~g}$ ) of a non-toxic and inexpensive material $\left(\mathrm{NiFe}_{2} \mathrm{O}_{4} @ \mathrm{SiO}_{2}\right.$-FHS) as the catalyst. The mild reaction conditions, high yields, short reaction times, easy work-up, and absence of any volatile and hazardous organic solvents are some of the advantages of this protocol. Compared with non-magnetic NP catalytic systems, the presented protocol combines the advantages of solid Brönsted acids and MNPs. Also, the new catalyst can be effectively reused. Based on its satisfactory catalytic properties, the catalyst is a potential substitute for some commercial catalysts.

\section{Acknowledgments}

The authors are grateful to Ferdowsi University of Mashhad for financial support.

\section{References}

[1] Lim C W, Lee I S. Nano Today, 2010, 5: 412

[2] Shylesh S, Schuenemann V, Thiel W R. Angew Chem Int Ed, 2010, 49: 3428

\section{Graphical Abstract}

Chin. J. Catal., 2014, 35: 376-382 doi: 10.1016/S1872-2067(14)60001-2

\section{Ferric hydrogen sulfate supported on silica-coated nickel ferrite nanoparticles as new and green magnetically separable catalyst for 1,8-dioxodecahydroacridine synthesis}

Amir Khojastehnezhad*, Mohammad Rahimizadeh, Hossein Eshghi, Farid Moeinpour, Mehdi Bakavoli

Ferdowsi University of Mashhad, Iran; Islamic Azad University-Bandar Abbas Branch, Iran

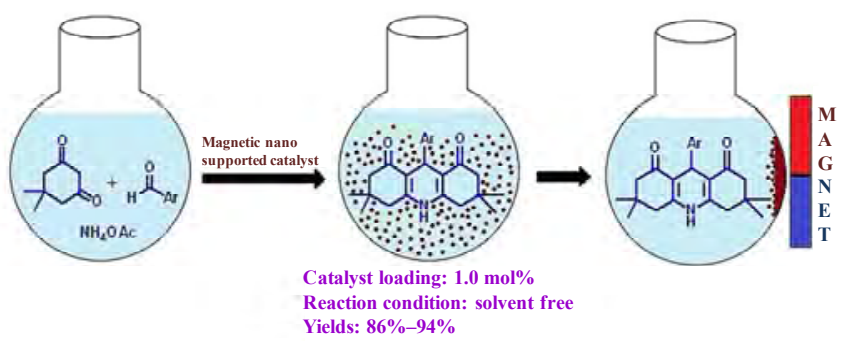

A new magnetically separable catalyst consisting of ferric hydrogen sulfate supported on silica-coated nickel ferrite nanoparticles was prepared and was shown to be an efficient heterogeneous catalyst for the synthesis of 1,8-dioxodecahydroacridines under solvent-free conditions. The catalyst was readily recovered by simple magnetic decantation and was recycled several times with no significant loss of catalytic activity. 
[3] Riente P, Mendoza C, Pericas M A. J Mater Chem, 2011, 21: 7350

[4] Abu-Rezig R, Alper H, Wang D, Post M L.J Am Chem Soc, 2006, 128: 5279

[5] Qiang Y, Antony J, Sharma A, Nutting J, Sikes D, Meyer D. J Nanopart Res, 2006, 8: 489

[6] Kong A G, Wang P, Zhang H Q, Yang F, Huang S P, Shan Y K. Appl Catal A, 2012, 417-418: 183

[7] Sato Turtelli R, Duong G V, Nunes W, Groessinger R, Knobel M. J Magn Magn Mater, 2008, 320(14): e339

[8] Cannas C, Ardu A, Musinu A, Peddis D, Piccaluga G. Chem Mater, 2008, 20: 6364

[9] Piao Y, Burns A, Kim J, Wiesner U, Hyeon T. Adv Funct Mater, 2008, 18: 3745

[10] Eshghi H, Seyedi S M, Safaei E, Vakili M, Farhadipour A, BayatMokhtari M. J Mol Catal A, 2012, 363-364: 430

[11] Eshghi H, Rahimizadeh M, Hosseini M, Javadian-Saraf A. Monatsh Chem, 2013, 144: 197

[12] Spalding D P, Chapin E C, Mosher H S. J Org Chem, 1954, 19: 357

[13] Gamega S A, Spicer J A, Atwell G J, Finlay G J, Baguley B C, Deny W A. J Med Chem, 1999, 42: 2383

[14] Antonini I, Polucci P, Kelland L R, Menta E, Pescalli N, Martelli S. J Med Chem, 1999, 42: 2535

[15] Ngadi L, Galy A M, Galy J P, Barbe J, Cremieux A J, Chevalier J, Sharples D. EurJ Med Chem, 1990, 25: 67

[16] Berkan O, Sarac B, Simsek R, Yildirim S, Sarioglu Y, Safak C. Eur J Med Chem, 2002, 37: 519

[17] Murugan P, Shanmugasundaram P, Ramakrishnan V T, Venkatachalapathy B, Srividya N, Ramamurthy P, Gunasekaran K, Velmurugan D. J Chem Soc, Perkin Trans 2, 1998: 999

[18] Tu S J, Miao C B, Gao Y, Fang F, Zhuang Q Y, Feng Y J, Shi D Q. Synlett, 2004: 255

[19] Rafiee E, Eavani S, Khodayari M. Chin J Catal (催化学报), 2013, 34:
1513

[20] Davoodnia A, Zare-Bidaki A, Behmadi H. Chin J Catal (催化学报), 2012, 33: 1797

[21] Ghasemzadeh M A, Safaei-Ghomi J, Molaei H. Compt Rend Chim, 2012, 15: 969

[22] Nemati F, Heravi M M, Saeedi Rad R. Chin J Catal (催化学报), 2012, 33: 1825

[23] Davoodnia A, Khojastehnezhad A, Tavakoli-Hoseini N. Bull Korean Chem Soc, 2011, 32: 2243

[24] Rashedian F, Saberi D, Niknam Kh.J Chin Chem Soc, 2010, 57: 998

[25] Shen W, Wang L M, Tian H, Tang J, Yu J J. J Fluorine Chem, 2009, 130: 522

[26] Suarez M, Loupy A, Salfarn E, Moran L, Rolando E. Heterocycles, 2009, 51: 21

[27] Dabiri M, Baghbanzadeh M, Arzroomchilar E. Catal Commun, 2008, 9: 939

[28] Fan X S, Li Y Z, Zhang X Y, Qu G R, Wang J J. Heteroatom Chem, 2007, 18: 786

[29] Moeinpour F, Khojastehnezhad A. E-J Chem, 2012, 9: 504

[30] Khojastehnezhad A, Moeinpour F, Davoodnia A. Chin Chem Lett, 2011, 22: 807

[31] Moeinpour F, Sardashti-Birjandi A, Dorostkar-Ahmadi N, Khojastehnezhad A, Mohseni-Shahri F S. Synth React Inorg Met-Org Nano-Met Chem, 2012, 42: 278

[32] Zins D, Cabuil V, Massart R. J Mol Liq, 1999, 83: 217

[33] Chandrasekhar S, Srinivasa Rao S, Sreelakshmi L, Mahipal B, Reddy C R. Synthesis, 2008: 1737

[34] Javid A, Khojastehnezhad A, Heravi M, Bamoharram F F. Synth React Inorg Met-Org Nano-Met Chem, 2012, 42: 14

[35] Balalaie S, Chadegani F, Darviche F, Bijanzadeh H R. Chin J Chem, 2009, 27: 1953

[36] Hong M, Xiao G M. J Fluorine Chem, 2012, 144: 7 